\title{
3. PRACTICE THROUGH MOVEMENT AND PRACTICE THROUGH MOTIONLESSNESS
}

\author{
Ana-Cristina Leșe ${ }^{106}$
}

\begin{abstract}
Through this paper we address the students from theatre and music specialists, but also all people interested in elements belonging to Tai Chi practice, considering that these, once introduced into a specific physical exercise program, are beneficial for the development of the respiratory capacity and also for a good physical and mental balance that support the professional skills. These two expressions used in the majority of martial arts, dung-gong movement practice and jing-gong motionless practice are yin and yang aspects and are based on the balance between motion and stillness of the body and the mind.
\end{abstract}

Key words: Tai Chi, physical, mind, theatre, music

\section{Introduction}

The movement practice involves the external movements of the body but in close co-operation with the inner motion of the mind. In the martial arts we also meet the expression "meditation through motion". The exercises through movement are characterized by: easiness, slowness, gentleness of movement, balance in physical postures and synchronization of body movements with the pace of respiration. The purpose of motion exercises is to keep the moving parts of the body flexible, to stimulate energy and blood circulation through the body, and to harmonize the movements of the body with internal energies.

A very important indication in motion practice is „,searching for stillness in motion". This expression leads us to the renowned director and playwright Eugenio Barba, who I mentioned in the previous lines and who emphasized this aspect in the paper „The paper canoe: a treatise on theatre anthropology” . The Odin Theatre, led by the Danish director Eugenio Barba, was also a laboratory for the training of actors based on methods founded on the teachings of Master J. Grotowski and Asian traditions.

\section{Discussions}

This Treaty of theatrical anthropology begins with a series of questions: „Why, while performing the same actions, an actor is credible, and another one is not?”, „Is talent also a technique?”, “A still-moving actor can maintain the spectator's attention alive?”, “What makes the energy in theatre?”. As far as the acting game is concerned, we have, first of all, taken into consideration the ideas about physical and mental training: positioning of the spinal column, weight of the body, balance, direction of the eyesight, muscle contractions and tensions, spontaneity, attention, concentration, all which produce physical expressions or pre-expressive tensions, as Eugenio Barba calls them.

\footnotetext{
106 Lecturer PhD., "George Enescu" National University of Arts from Iaşi, Romania, email: analese2000@yahoo.com
} 
The essence of theatrical Anthropology, constructed by the Italian theater, is the study of pre-expressive scenic behavior, which includes pre-expressive techniques, pre-expressive actions, all of which include different actor's techniques, conscious and coded or unconscious, but which are involved in the realization and repetition of the theatrical practice.

The position of the body in the forms of movement is also very important. We mention again the same author, Eugenio Barba, who brings clear arguments in his teaching system in preparing the actors, stating that: a very important attitude and skill adopted by the actors at the Odin Theater in their preparation is the position of sats or the moment of sats, that is, the moment „ready to act and to react at any moment". The author explains this state as "the basic posture found in sports: tennis, badminton, boxing, fencing, whenever you have to be ready to react ${ }^{\prime 107}$.

The position „ready to attack” or „sats” in which the knees are very slightly bent, thus facilitating the easy distribution of the centre of weight at a fast pace and in any direction, did not have the training as an end in itself but was born as an actor's tendency following the numerous training sessions. Eugenio Barba gives great importance to the term sats in the Theatrical Anthropology Treaty, explaining its meaning in several ways:

- a small discharge of energy that changes the course and intensity of the action or interrupts it unexpectedly;

- a moment of transition that leads to a new, precise posture, thus a change in the tone of the entire body;

- the technical explanation of the common place, according to which the actor has the gift of repeating the show in such a way that the action seems to happen for the first time;

- to know how to walk without asking yourself how to walk;

- a minuscule discharge, through which thinking embraces action and is thus felt as thought/action, energy, rhythm in space.

The meaning of these explanations is given by a well-trained psychomotor actor capable of stopping an action at any moment without muscle relaxation or discontinuing the representation of the action and offering „surprises” in the subsequent movements. The author finds a variation of sats and the technique of the actor initiated by J. Grotowski, known as „premovement”, „a kind of silence before the movement, a silence loaded with potential or that can be realized as a stop to action in a certain moment".

Eugenio Barba continues his argument, pointing out that in Etienne Decroux the term sats is expressed by "motionless motion”, that for the same sats, V. Meyerhold uses the terms „pre-play”; „predigheth” and „rhythm brakes” ${ }^{108}$. In the Japanese theatre, sats is designated by a precise Japanese term, tangkis - which means transition, moving from one posture to one another, from one level to another.

\footnotetext{
${ }^{107}$ see Jane Turner, Eugenio Barba, Routledge, Taylor\&Francis Group, London and New York, 2004, p.13

108 Barba, Eugenio, The paper canoe: a treatise on theatre anthropology, translation from Italian and foreword by Liliana Alexandrescu, Bucureşti, UNITEXT Publishing House, 2003.p. 17
} 
At the Peking Opera House (Beijing), certain sats (impulsecounterimpuls) stand out in particular: „The actor quickly executes a series of movements and at the height of the tension stops in an unstable equilibrium position - lian shan - ready to start in a direction that will surprise the spectator's expectations" 109 .

In a similar context, the term sats is translated into „motion can be blocked, but it does not stop inside". The great director and teacher Evgheni Vahtangov called „living in breaks” the ability to take a position and justify internal tension. K.S. Stanislavski, for the same position, offered the explanation: „Stand still, keeping the rhythm.” Here’s how Eugenio Barba finds common points ("meeting points") in the actor's preparation, to theatre people who have marked the actor's technique in the 20th century, embodied in everybody's specific methods.

Our interest in „moving in motionlessness” leads us to believe that physical actions must be convincing: they must be prepared in advance with skill, to the smallest details, using and adapting physical and mental exercises for each muscle contraction, for breathing, voice, gesture and mimics.

We believe that few professions require such a psycho-motor training, and the way in which actors, musicians and athletes are trained - to achieve their goals, draws our attention to the highest degree. In this regard, the theatrical anthropology helps us with priceless suggestions. Practice through motionlessness is essentially characterized by the external motion of the body combined with the internal energy movement, which is also called „searching for motionlessness", as Eugenio Barba specified.

The meditation forms (exercises) can be practiced from sitting, standing or lying. „Unlike concentrating on body synchronization with breathing, as in the form of motion, in the practice of motionlessness, the focus falls on keeping the mind in perfect agreement with breathing"110. An important recommendation in exercises the practice of motionlessness is body preparation through relaxation exercises, balancing, stretching, just as the mind needs to be quiet and the emotions calm down.

3. In conclusion, motion and motionlessness exercises are specific to all styles of martial practice. The forms of movement are represented more by the body and by the external aspects of the practice, and the exercises through stillness are represented more with the mind and with the internal aspects, breathing having the role of a functional link between motion and motionlessness, between the inner and outer, between the mind and body. In Tai Chi Practice we find forms both in motion and in motionlessness.

\footnotetext{
${ }^{109}$ Barba, Eugenio, pp.94-9

110 Daniel Reid, Qi gong, manual de inițiere, translation by Cristina Popa, Polirom Publishing House, Iași, 2005, pp.74-75
} 


\section{Bibliography}

1. Barba, Eugenio, 2003, The paper canoe: a treatise on theatre anthropology, translation from Italian and foreword by Liliana Alexandrescu, UNITEXT Publishing House, Bucureşti.

2. Jane Turner, 2004, Eugenio Barba, Routledge, Taylor\&Francis Group, London and New York.

3. Reid, Daniel, 2005, Qi gong, manual de inițiere, translation by Cristina Popa, Polirom Publishing House, Iași. 